\title{
Facilitators of and barriers to clinical supervision of speech-language pathology students in South Africa: A pilot study
}

\author{
A Mupawose, $\mathrm{PhD}$ (Speech pathology); S Adams, MA (Speech pathology); S Moonsamy, $\mathrm{PhD}$ (Speech pathology) \\ Department of Speech Pathology and Audiology, School of Human and Community Development, University of the Witwatersrand, Johannesburg, South Africa
}

Corresponding author: A Mupawose (anniah.mupawose@wits.ac.za)

\begin{abstract}
Background. Clinical supervision plays a fundamental role in maintaining professional standards when training students of professional degrees at a university undergraduate level.

Objective. To describe the perceptions of clinical educators regarding the facilitators of and barriers to learning when training undergraduate speech language pathology students in underserved and under-resourced clinical contexts in Gauteng, South Africa.

Methods. A qualitative approach, using a focus group discussion, was employed. Data were gathered from 8 clinical educators regarding their experiences of supervision of students. Themes were identified and analysed using thematic analysis.

Results. Themes generated revealed that there were barriers in supervision due to attitudes of student clinicians, clinical educators' preparedness and infrastructure at clinical sites. Facilitators of the supervisory process were identified as feedback from student clinicians and support given by the department to clinical educators.

Conclusion. These findings suggested that clinical educators require additional time, support and training to assist them with clinical supervision As clinical supervision is fundamental to the speech-language pathology curriculum and student experience, its value should not be underestimated These findings contribute to the process of transforming the effectiveness of clinical supervision.
\end{abstract}

Afr J Health Professions Educ 2021;13(1):23-28. https://doi.org/10.7196/AJHPE.2021.v13i1.1216

Clinical supervision supports the speech-language pathology student's application of theory to diagnostic assessment and therapeutic intervention practices. The process of supervision includes the 'observation, facilitation, acquisition of knowledge and skills, guidance and assessment of any student interaction. ${ }^{[1]}$ Furthermore, clinical supervision plays a vital role in maintaining professional standards in the training of students in undergraduate and postgraduate professional degrees such as medicine, social work, nursing and speech-language pathology (SLP).$^{[2,3]}$ According to the American Speech and Hearing Association (ASHA), ${ }^{[4]}$ the supervisory process is the interaction that takes place between the clinical educator and the student clinician. The success of this interaction may be related to the behaviour of the student clinician, clinical educator, client or the training programme in which the clinical educator and student clinician are involved. ${ }^{[5]}$ Therefore, the goal of clinical supervision is to facilitate the professional growth and development of the clinical educator and student clinician to provide optimal service to the client(s).

Clinical supervision is undergirded by a developmental approach, which requires clinical educators to change their expectations of clinical practice in accordance with the level of clinical preparedness of the student clinician. Previous research has indicated that clinical educators' expectations of students are based on their own prior experience and personal values. ${ }^{[6,7]}$ These expectations result in biases and sources of error when acting as a clinical educator. Thus, there is a need to collect behavioural data and information on the student clinicians' and clinical educators' personal perceptions. Obtaining these data and information can positively improve clinical supervision by influencing the development of the clinical curriculum. If the curriculum is improved, then service delivery to linguistically and culturally different clientele is also improved.
Questions concerning clinical educators' biases and the differential effects of supervising student clinicians from linguistically and culturally different backgrounds were explored in a study by Keeton et al..$^{[1]}$ The study was conducted in Johannesburg, South Africa (SA), where 8 clinical educators were interviewed regarding their experiences working with diverse students in underserved contexts. Results indicated that clinical educators struggled with supervising students from linguistically and culturally diverse backgrounds, which affected their assessment of student clinicians. Furthermore, the student clinicians' effectiveness in providing appropriate client intervention was reduced. These findings highlight the need to understand ways in which clinical educators can be supported and the challenges that they experience working with students from linguistically and culturally different backgrounds within underserved and underresourced contexts. Furthermore, to evaluate the efficacy of the supervisory process, empirical documentation is needed. In this article, we argue that it is important to identify facilitators and barriers in the supervision process, which will enable the department to improve the clinical curriculum to address the needs of students, clinical educators, and clients at the various sites.

\section{Clinical educators in speech-language pathology at the University of the Witwatersrand, Johannesburg}

Clinical educators have an important role in training student clinicians, as well as ensuring that clients receive relevant interventions. To embody both, clinical educators must understand the needs of the student, the context and the university's initiatives and policies. ${ }^{[8]}$ Currently, the university has called for a transformed curriculum that is inclusive of student demographics 
and contextually relevant instruction. ${ }^{[1]}$ The pedagogical knowledge and praxis of clinical educators must be in step with the curriculum changes. At the University of the Witwatersrand, the SLP department relies heavily on clinical educators, who are contracted as sessional staff. This process has often resulted in discrepancies in operation between departmental and clinical level. Previous research has highlighted the challenges different health science training programmes have in working with clinical educators, particularly part-time or sessional staff. However, there is limited research on clinical educators facilitating clinical learning with students from diverse backgrounds in underserved contexts. Challenges previously reported in the literature include the teaching of students who are culturally and linguistically different from the clinical educators, availability of clinical educators to students, and how feedback is provided..$^{[1,3,5,9-12]}$ It is, therefore, fundamental that clinical educators identify and apply models of best practice, based on research of the supervisory processes that are relevant to the SA context. However, this can only be done through examination of current practices and the creation of models that can be used with current clinical educators and the current student population.

Clinical training of students involves direct instruction and mentoring, which are subject to change, depending on the students' competency level. However, providing direct instruction can be hampered when clinical educators have not kept abreast with the latest information; provided additional time to work with weaker students; or modelled the correct techniques or behaviours. Modelling students requires more time, which is not always feasible, as clinical educators assist students of varied abilities and learning styles. Furthermore, direct instruction or mentoring can be affected by clinical educators working at placement sites off campus. When clinical educators are off campus, they are not readily available to assist students who may need them. ${ }^{[11]}$ Since clinical educators often do not work daily in an academic space, they sometimes regard patient care as more important than teaching and mentoring of student clinicians. However, clinical educators need to hold patient care and student clinical teaching in the same regard to improve the supervisory process.

Feedback is important in the supervision process. Feedback from clinical educators can either be verbal or written and should reflect where the student is along the continuum of learning clinical work. ${ }^{[3,5,12]}$ However, feedback can be difficult for clinical educators when students are not willing to receive it. Feedback from clinical educators also informs the clinical curriculum and enables the department to provide the necessary support for students. This highlights the need for empirical documentation of clinical educators' experiences and opinions on the effectiveness of the clinical curriculum, as well as their own supervisory processes.

\section{Clinical supervision model}

There is no universally agreed-upon model of supervision in SLP. ASHA $^{[4]}$ recognises Anderson's ${ }^{[13]}$ continuum model, which is based on the developmental constructs that span a professional career. Anderson's continuum model is based on the premise that the amount and type of supervision change over time, as does the role of the clinical educator and student clinician. In Anderson's model, the student progresses through three broad stages of supervision: evaluation-feedback, transitional and self-supervision. Anderson's model also describes how the clinical educators' style of supervision (direct/active, collaborative, consultative) changes as the students progress through the abovementioned three stages. However, the literature has shown that clinical educators do not modify their behaviour relative to the students' experience, knowledge, and developmental stage. ${ }^{[14]}$ The incongruence between what clinical educators state and what they do, has been evident at clinical tutor meetings hosted by the department.

Recent advances in the arena of clinical supervision are being driven by a call for higher patient safety and evidence-based practice. This shift in correlating clinical supervision with quality health or rehabilitation services supports the need for formalising clinical supervision in SLP. As a department, we need to determine how efficacious clinical supervision is in working with diverse students in underserved contexts The aim of this study was to determine what the clinical educators' facilitators and barriers are in the supervision of SLP students. This article argues that an understanding of clinical educators' experiences and perceptions of supervising students have explicit implications for student training in SLP.

\section{Methods}

Research question: What are the perceptions of clinical educators about the supervisory process regarding supervision of undergraduate SLP students in Gauteng?

\section{Research objectives}

- To identify and describe the barriers to the supervisory process of undergraduate SLP students in Gauteng.

- To identify and describe the facilitators of the supervisory process of undergraduate SLP students in Gauteng.

\section{Research design}

A qualitative, exploratory research design using a focus group was employed in this study. The design allowed the researchers to gain insight in and explore the depth and complexity of the supervisory process among clinical educators.

\section{Context}

Second- and third-year SLP students are sent to clinical placement sites to provide therapy, twice a week for 7 weeks. Students spend 3 hours at the placement site providing both individual and group therapy sessions under the supervision of a clinical educator. Clinical language sites are in underserved, under-resourced and densely populated areas of Johannesburg. The clinical educator to student ratio is generally 1:6.

\section{Participants}

A purposeful convenience sampling strategy was used to select both secondand third-year clinical educators involved in supervising undergraduate SLP students in primary school contexts. The sample was represented by 8 clinical educators; all were female, with varying levels of experience. The 8 participants were recruited at a clinical educators' meeting that is held bi-annually in the department. The inclusion criteria stipulated that clinical educators needed to be registered with the Health Professions Council of South Africa (HPCSA) (professional accreditation body) and have a minimum of 2 years' work experience after graduation and community service. ${ }^{[15]}$ The HPCSA mandates that graduates in the profession may clinically supervise after working for 2 years. ${ }^{[15]}$ The participants were also required to be proficient in English because it is the language of learning and teaching at the University of the Witwatersrand. The description of the participants is shown in Table 1. 


\section{Data collection}

An interview schedule was used, and open-ended questions were generated from the relevant literature.

After the departmental clinical educators' meeting, participants were informed about the purpose and details of the study. All questions raised were answered. Participation was voluntary and participants could leave at any time during the focus group discussions. Once the consent forms were signed, focus group discussions began on the supervisory process. All these discussions were conducted in English. The focus groups were moderated by an experienced facilitator hired and orientated to the research study. The focus group discussions lasted $\sim 1$ hour. Data responses were audio-recorded and then transcribed verbatim. Any personal or identifying information mentioned by the participant was omitted from the transcript to maintain confidentiality.

\section{Data analysis}

Data were analysed according to the Braun and Clarke ${ }^{[16]} 6$-step procedure of thematic analysis, which included reviewing the data to become familiar with it, generating initial codes, searching for themes, reviewing potential themes, defining and naming themes and, finally, reporting on findings. The analysis of the data started with the researchers (re)reading the transcripts and listening to the audio-recordings to make notes. The purpose of the notes was to get a deeper understanding of what the participants were stating. Then the researchers started the process of identifying and generating codes for potential themes. The initial codes included the actual meanings of what was stated and the researchers' interpretation of it. After initial codes were generated, each researcher proceeded to search for themes. Once each researcher had identified themes and reviewed them again for further analysis, they came together to compare, define and name agreed-upon themes for final reporting.

\section{Trustworthiness}

Trustworthiness was determined via credibility, dependability, and confirmability. Credibility was determined by member checking, whereby the written responses were sent to participants to determine whether the researchers had captured the essence of what they wanted to convey. ${ }^{[17,18]}$ Dependability was achieved by detailing all aspects of the methodology, such as research design, description of participants, data collection, compilation of transcripts and data analysis. Finally, confirmability was established by the researchers stating their position in terms of epistemology to represent the participants' perspectives as unbiased.

\section{Ethical approval}

Ethical clearance was granted by the Human Research Ethics Committee of the University of the Witwatersrand (ref. no. H18/11/24).

\section{Results and discussion}

Results are discussed in accordance with the research aims, as indicated in Table 2.

\section{Barriers to the supervisory process Attitudes of students}

Three out of 8 clinical educators reported that student clinicians did not always have a 'good' attitude during clinical sessions at the sites. The attitudes shown by students made it difficult for clinical educators to give feedback and
Table 1. Description of participants $(N=8)$

\begin{tabular}{ll}
\hline Variables & $\boldsymbol{n}(\%)$ \\
\hline Race & $2(25)$ \\
Black & $3(37.5)$ \\
White & $2(25)$ \\
Indian & $1(12.5)$ \\
Coloured & \\
Supervising, years & $3(37.5)$ \\
$0-2$ & $3(37.5)$ \\
$3-5$ & $2(25)$ \\
$>5$ & \\
Clinical site & $2(25)$ \\
Children's home & $2(25)$ \\
Crèche & $4(50)$ \\
School &
\end{tabular}

Table 2. Research aims and themes

\begin{tabular}{ll}
\hline Aims & Themes \\
\hline Barriers to supervision & Attitudes of students \\
& $\begin{array}{l}\text { Supervisor preparedness } \\
\text { Infrastructure at the clinical site }\end{array}$ \\
Facilitators to supervision & Feedback \\
& Departmental support
\end{tabular}

constructive criticism, as students did not receive the feedback favourably:

'Students do not always do the things I ask them and get very defensive. I also find that these students are not always implementing feedback and changes that have been suggested to them.' (Participant 2)

These findings are similar to those of Davies et al. ${ }^{[19]}$ in their study of physiotherapy clinical educators. They found it stressful and difficult giving feedback to failing or borderline-performing students. Failing students were an added burden to clinical educators. Clinical educators reported that failing students required extra time, induced emotional stress, and sometimes presented with difficult personality (e.g. be overly emotional, overconfident, immature or have a poor work ethic). Wium and du Plessis ${ }^{[12]}$ suggest that students need to become better at self-assessment, as those who are less competent tend to overestimate their clinical competence, making them less open to constructive feedback and change. A lack of self-assessment or reflection does not allow students to identify their areas of weakness and how they can improve these. Therefore, it is imperative that reflection comprises part of clinical training for student clinicians. Students need to be shown how to reflect and given time to reflect on their performance. Reflective practice is one pillar in metacognition - monitoring and evaluation being the other two. Moonsamy ${ }^{[20]}$ states that, for this process to be effective, metacognition should happen before, during and after the intervention process. Therefore, clinical educators need to exercise metacognition so that they can share their learning with students. This can be done using guided reflections so that both student clinicians and clinical educators can understand why students do what they do, why they feel in a particular way and how to best support them. Furthermore, students often focus on marks and do not have a broader vision of learning and development. Consequently, if the supervisory process develops a value-add proposition, student SLPs should transform their attitudes and see learning as a life-long attribute. 


\section{Supervisor preparedness}

Five of 8 clinical educators felt that students were not adequately prepared for the clinical setting. Clinical educators reported that students did not have appropriate theoretical knowledge because they struggled to apply and integrate theory with clinical practice.

One supervisor commented on the impact that one weak student can have on other students due to the additional time needed to support that student:

'It is difficult when you have a weak student at the clinic, because of the supervisor-student ratio it takes time away from the other students. I end up spending more time mentoring that [weak] student because they do not know what they are doing.' (Participant 4 )

These findings are supported in a study by Kilminster and Jolly, ${ }^{[21]}$ where the importance of the structure and content of a clinic as reasons for the level of preparedness was commented on. In their study, many students felt that too much time was spent on case reviews and not enough on explaining theoretical issues or teaching related practical concepts. ${ }^{[2]}$ Students generally are aware that they may have difficulty with the application of knowledge; therefore, clinical educators need to know that their role goes beyond mentoring and includes teaching ${ }^{[9]}$ Didactic training can be a powerful tool for enhancing student knowledge. However, clinical educators report that there is not always enough time at the clinic placement site to provide appropriate patient care, teach students and give feedback. ${ }^{[1]}$ The levels of preparedness, therefore, can be attributed to the student and the clinical educators' management and logistics. The levels of preparedness highlight the importance of students and clinical educators needing a clear idea of what they are doing and the expectations they have of each other. Clinical educators should be provided with time to prepare, which should be built into their workload, as patient care and student training should be prioritised when working with students. ${ }^{[1]}$ Clinical educators should be given scope to further their own knowledge and training through research and continuing education forums to enhance their knowledge of student supervision.

\section{Infrastructure at the clinical site}

Six of 8 clinical educators identified the clinical placement sites as a barrier to clinical supervision in terms of resources, services available and physical space. Although many sites required SLP services, clinical educators reported that many of them did not have space to accommodate all the students:

'There are lots of children that need therapy, and the site is in dire need of services. But space is problematic for six students ... (Participant 4)

Many clinical educators reported having to work in the hallway or outside:

'We struggle a bit with space ... we tend to try and use the corners of the room or find space outside.' (Participant 5)

Clinical educators also reported that the limited resources added additional stress to their clinical work. Clinical educators reported feeling stressed because they had the added responsibility of negotiating and finding spaces for students to conduct therapy. Sometimes the identified spaces were not conducive to optimal language therapy. One supervisor working at a school reported the following:

'The school is very poor, and they do not have chairs. They do not always want to give us desks to use and I end up having to look for chairs,
I have to keep telling them [the students] to be more independent.' (Participant 1)

Previous studies have reported that the context students work in can impact negatively on their experience. ${ }^{[12,21]}$ However, this is a barrier that is difficult to overcome in SA, where there is a need for services, but a lack of available resources. Student clinicians and clinical educators need to become responsive to the context they are working in and be creative in where and how to work at the different sites.

\section{Facilitators of the supervisory process Feedback}

Students were given an opportunity to provide written feedback on the clinical training experience and their clinical educators. This feedback was shared with the clinical educators, but the anonymity of the student was maintained. All 8 clinical educators reported on how student feedback had helped them to improve their supervision style and to understand what the students were thinking and feeling:

'Supervisor feedback was very helpful as you can get into the head of the students and see what difficulties they are having. You can also change your ways, and it helps you to see where they are coming from. (Participant 8)

Another clinical educator commented on how it helped her to grow in her supervision, and she sees the difference in the students:

'The feedback helped me to see what was and was not working for the students. I was able to adjust what I was doing and saw an improvement in the students and how they were performing at the clinic.' (Participant 2)

Gonsalvez et al. ${ }^{[9]}$ emphasise the importance of anonymised feedback as a way to measure clinical educators' performance and that it should be given consistently throughout the placement. This needs to be built into the clinical environment as a form of evaluation and to address issues at the site and with the clinical educators. Furthermore, clinical educators need to be aware of the power relations inherent in the supervisory relationship and evaluate how they provide feedback so that the student clinician does not feel powerless. Likewise, clinical educators need to be aware of their positionality, cultural biases, or stereotype 'thinking' they bring to the clinical educator and student relationship. ${ }^{[22]}$ Being mindful of bias is critical, especially bearing in mind SA's history of discrimination.

\section{Departmental support}

All 8 clinical educators commented on the importance of departmental support and how this assisted with supervising the clinic.

One of the participants remarked on the type of support the department could include:

'Communication on dates and what is due when, constant emailing to find out the protocol ... when we are assessing etc. ... perhaps send us a guideline before the clinic commences as it is difficult to keep consulting the students - we need to be in control.' (Participant 6)

The same participant suggested more communication with the lecturers:

'... need to be informing the lecturers more on what is happening in therapy' (Participant 6) 
The comments made by participants reflect that improved communication between internal and external clinical staff in training institutions is fundamental. The clinical educators commented that they would like more training and time to see the students on a one-to-one basis. These comments have been supported by Dudding et al. ${ }^{[22]}$ and Davies et al. ${ }^{[19]}$ With regard to training, research in the nursing discipline has correlated clinical supervision with improvements in the quality of patient care. ${ }^{[22]}$ The field of medicine also argues that efficient supervision improves patient care. Despite knowing that quality supervision improves patient outcomes, there are no international or national formalised training requirements for clinical education in SLP.

Institutional support is very important, ${ }^{[9]}$ as it provides the training department with the finances to hire more staff and decrease the workload of clinical educators, allowing more time to prepare and engage with students. Moreover, by reducing the caseload of clinical educators, the importance of paying detailed attention is valued. Developing student skills is very essential in the consolidation of learning and application. This is paramount, especially as the cohort of SLP students have diverse learning needs. Given the history of SA's education systems, most students would benefit from academic and clinical support.

\section{Conclusion}

In concluding, the findings of the study highlight clinical educators' perceptions about supervision in relation to students, infrastructure, and feedback. Reflecting on the input from clinical educators confirms their required support from the training programme. Furthermore, a collaborative relationship should exist between clinical educators and students, and the training institution and clinical educators. For an effective collaborative relationship, open channels of communication are needed. ${ }^{[23]}$ Clinical training, therefore, needs to create awareness in students regarding introspection, insight, and metacognition. Research has shown that the more knowledgeable person in the supervisory process needs to demonstrate their reflective thoughts so that students can learn how clinical educators think. All clinical educators need to practise and model their way of critical thinking. Modelling critical thinking would allow students to recognise their own thinking, as well as new ways of thinking. Students should then feel confident in making their thinking explicit in their planning and practice of SLP therapy. Clinical educators and students should also work collaboratively with individuals at each community site so that the solutions identified are relevant to the context. This, as indicated in the article, begins with training so that clinical educators take on the responsibility of being agents of change. Curriculum transformation needs to include real, rather than ideal, contexts so that students' practice is appropriate.

\section{Study limitations and future directions}

Most studies are cross-sectional, and it would be beneficial to provide clinical educators with training or an intervention and then measure the outcomes longitudinally. The study utilised a focus group that facilitated the construction of meaning from collective discussion and conversations. ${ }^{[24]}$ However, in the future, it may be beneficial to interview individual participants and obtain more in-depth responses that are not influenced by others' perspectives. The current research study identified that clinical educators favour additional tools and strategies to help them to enhance the supervisory process, which needs to be implemented and evaluated.
Another direction for this research would be to apply the same instrument to an increased number of clinical educators in the same and in different educational fields. In addition, student perceptions on the facilitators of and barriers to learning while at clinical practicum could also be explored.

\section{Implications}

As many clinical educators are not always in the academic space, opportunities for ongoing training should be incorporated by the department. Clinical educators should be given scope to further their own knowledge and training to enhance the learning experience of the students. Students need to meet outcomes for clinical training set out by statutory bodies (e.g. the HPCSA); however, the context in which they are working should also be considered. The department needs to support sessional clinical educators and make sure their workload is manageable and that they have adequate time to prepare for clinical teaching, as they not only need to provide high-quality patient care but also theoretical teaching. The findings of this research highlight the importance of formalised training for clinical educators and better institutional communication. This study, therefore, contributes to understanding the facilitators of and barriers to the supervisory process of diverse students in underserved contexts. It has provided input into models of best practice and ways to improve clinical training and client service delivery.

\section{Declaration. None.}

Acknowledgements. The authors would like to thank all participants for their feedback.

Author contributions. AM facilitated the focus group discussion, applied for ethical clearance, and wrote the literature review. SA wrote the methodology and results and discussion. SM added information to the literature review and wrote parts of the results and discussion, and wrote the conclusion.

Funding. None.

Conflicts of interest. None.

Keeton N, Kathard H, Singh S. Clinical educators' experiences of facilitating learning when speaking a different language from both the student and client. BMC Res Notes 2017;10(1):1-8. https://doi.org/10.1186/s13104-0172874-4

2. Culloty T, Milne DL, Sheikh AI. Evaluating the training of clinical supervisors: A pilot study using the fidelity framework. Cogn Behav Ther 2010;3(4):132-144. https://doi.org/10.1017/\$1754470X10000139

3. Milne D. Can we enhance the training of clinical supervisors? A national pilot study of an evidence-based approach. Clin Psychol Psychother 2010;17(4):321-328. https://doi.org/10.1002/cpp.657

4. American Speech-language and Hearing Association. Clinical supervision in speech-language pathology. 2008 www.asha.org/policy (accessed 22 July 2018).

5. Wright J, Needham C. The why, who, what, when, and how of supervision. Perspect ASHA Spec Interest Groups 2016;1(11):68-72. https://doi.org/10.1044/persp1.SIG11.68

6. Gillam RB, Roussos CS, Anderson JL. Facilitating changes in supervisees' clinical behaviors: An experimental investigation of supervisory effectiveness. J Speech Hear Disord 1990;55(4):729-739. https://doi.org/10.1044 jshd. 5504.729

7. Burkard AW, Johnson AJ, Madson MB, et al. Supervisor cultural responsiveness and unresponsiveness in croscultural supervision. J Couns Psychol 2006;53(3):288-301. https://doi.org/10.1037/0022-0167.53.3.288

8l Kadri HM, Al-Moamary MS, Elzubair M, et al Exploring factors affecting undergraduate medical students Al Kadr study strategies in the dinical years. A qualitative study. Adv Hanth Sci dac 2017:16(5):553-567. https://do

Gonsalvez C), Wahnon T, Deane FP. Goal-setting, feedback, and assessment practices reported by Australian Sychol 2017;52(1):21-30. https://doi.org/10.1111/ap.12175

10. Lee W-S, Cholowski K, Williams AK. Nursing students' and clinical educators' perceptions of characteristics of effective clinical educators in an Australian university school of nursing. J Adv Nurs 2002;39(5):412-420. https:// doi.org/10.1046/j.1365-2648.2002.02306.x

11. Schiekirka-Schwake S, Anders S, von Steinbüchel N, Becker JC, Raupach T. Facilitators of high-quality teaching in medical school: Findings from a nation-wide survey among clinical teachers. BMC Med Educ 2017;17(1):1-8. https://doi.org/10.1186/s12909-017-1000-6

12. Wium AM, du Plessis $\mathrm{S}$. The usefulness of a tool to assess reflection in a service-learning experience. Afr J Health Professions Educ 2016;8(2):178-183. https://doi.org/10.7196/AJHPE.2016.v8i2.586

3. Anderson JL. The Supervisory Process in Speech Language Pathology and Audiology. Boston: College Hill Press, 1988.

14. Geller E, Foley GM. Broadening the 'ports of entry' for speech-language pathologists: A relational and reflective model for clinical supervision. Am J Speech Lang Pathol 2009;18(1):22-41. https://doi.org/10.1044/10580360(2008/07-0053 


\section{Short Research Report}

15. Health Professions Council of South Africa. Regulations Relating to the Undergraduate Curricula and Professional Examination. Pretoria: HPCSA, 2012.

16. Braun V. Clarke V. Research designs: Quantitative, qualitative, neuropsychological, and biological. In: Cooper $\mathrm{HE}$ Camic PM, Long DL, Panter AT, Rindskopf DE, Sher KJ, eds. APA Handbook of Research Methods in Psycholog Vol. 2. Washington, DC: American Psychological Association, 2012:57-71. https://doi.org/10.1037/13620-004

17. Creswell JW, Miller DL. Determining validity in qualitative inquiry. Theory Pract 2010;39(3):124-130. https:// doi.org/10.1207/s15430421tip3903_2

8. Padgett D. Qualitative Methods in Social Work Research. Los Angeles: SAGE, 2008.

19. Davies R, Hanna E, Cott C. 'They put you on your toes': Physical therapists' perceived benefits from and barrier to supervising students in the clinical setting. Physiother Can 2011;63(2):224-233. https://doi.org/10.3138/ ptc.2010-07

20. Moonsamy S. Metacognition: A tool for strategic thinking teachers when mediating in the classroom. In Walton EL, Moonsamy S, eds. Making Education Inclusive. Newcastle Upon Tyne: Cambridge Scholars Publishing, 2015:113-129.
21. Kilminster SM, Jolly BC. Effective supervision in clinical practice settings: A literature review. Med Educ 2001;34(10):827-840. https://doi.org/10.1046/j.1365-2923.2000.00758

22. Dudding CC, McCready V, Nunez LM, Procaccini SJ. Clinical supervision in speech-language pathology an audiology in the United States: Development of a professional specialty. Clin Superv 2017;36(2):161-18 https://doi.org/10.1080/07325223.2017.1377663

23. Moonsamy S. Collaborative consultation. In. Moonsamy S, Kathard H, eds. Speech-language Therapy in a Schoo Context: Principles and Practices. Pretoria: Van Schaik, 2015.

4. Milward L. Focus groups. In: Breakwell GM, Hammond S, Fife-Schaw C, Smith JA, eds. Research Methods in Psychology. London: SAGE, 2006:274-299.

Accepted 16 January 2020 